\title{
Economic-mathematical model for complex risk assessment of the enterprise investment project using fuzzy logic
}

\author{
Inna Chaikovska ${ }^{1,2, *}$, Pavlo Hryhoruk ${ }^{2, * *}$, and Maksym Chaikovskyi ${ }^{2, * * *}$ \\ ${ }^{1}$ Leonid Yuzkov Khmelnytskyi University of Management and Law, 8 Heroiv Maidanu str., Khmelnytskyi, 29000, Ukraine \\ ${ }^{2}$ Khmelnytskyi National University, 11 Instytutska Str., Khmelnytskyi, 29016, Ukraine
}

\begin{abstract}
The article proposes an economic-mathematical model for determining a comprehensive risk assessment of the investment project of the enterprise which are based on the approaches of A. Nedosekin. The model is built using fuzzy logic and takes into account the probability of occurrence of each of the identified risks and the level of impact of each of them on the project. The probability of risk is set by experts in the form of points and converted into linguistic terms, and the level of influence of each of them on the project - the ratio of benefits and is determined using Fishburne scales. The proposed Project Risk Model consists of the following stages: formation of initial data using expert opinions; construction of a hierarchical project risk tree; determination of weight coefficients (Fishburne weights) of project risks; selection and description of membership function and linguistic variables; conversion of input data provided by experts from a score scale into linguistic terms; recognition of qualitative input data on a linguistic scale; determination of a complex indicator of investment project risks; interpretation of a complex indicator. The developed model allows managing the risks of the project to maximize the probability of its successful implementation, to compare alternative projects and choose less risky, to minimize the level of unforeseen costs of the project.
\end{abstract}

\section{Introduction}

\subsection{Problem description}

The following subsystems are distinguished in the project management system: time management [1], labor resources, cost, information and communications, quality, project risks, etc. Project risk management is one of the most important subsystems of project management because it allows at the planning stage of the project to identify problematic issues for its successful implementation. The comprehensive risk assessment of the project allows you to take into account the most significant risks for the project and quantify them to make an effectivelyinformed management decision. Quite often when assessing the risks of enterprise projects, the information is non-numerical, it is necessary to take into account both quantitative and qualitative information in one system and the formation of a single quantitative comprehensive indicator. To form a comprehensive risk assessment of the project, it is advisable to use fuzzy logic and obtain a comprehensive numerical risk assessment of the project.

If we consider the methods of risk identification, there will be many approaches only to the classification of risks. According to the common in foreign countries approach Construction Risk Management System (CRMS), proposed by American analysts, the process of risk identification consists of six stages: detection of uncertain-

\footnotetext{
*e-mail: inna.chaikovska@gmail.com

**e-mail: violete@ukr.net

***e-mail: larumlab@gmail.com
}

ties; compiling a preliminary checklist; consequence scenarios; a reflection of risks; systematic list of risks; total risk. Therefore, determining the total risk (complex value of project risks) is an urgent task. Besides, a comprehensive assessment should take into account both the probability of a risk event and the level of its impact on project implementation (weights). The obtained comprehensive assessment will determine whether it is appropriate to implement the project, what risks are most likely, and the level of impact on the successful implementation of the project, reduce the cost of the project, as well as make an effectively-informed management decision.

\subsection{Literature review}

The paper [2] identifies the need for effective methods of risk management in enterprises in modern conditions because the profitability of the enterprise largely depends on the level of risk. Also, risk allows you to assess the internal reserves of the enterprise and the level of risk depends on the feasibility of a particular financial and economic transaction. Risk management makes it possible to establish forecast quantitative estimates of economic performance of the enterprise.

The paper [3] states that in modern conditions it is necessary to use not only general methods of evaluation of investment projects. The use of various methods of evaluation of investment projects in one system will allow to make an informed management decision on the feasibility of their further implementation and ensure their flexibility. 
The paper [4] specifies that an investment project is a set of measures, works, and documents, the financial result of which is profit (income). The material result of the investment project is new or reconstructed fixed assets (objects). The project may also result in the acquisition and use of financial instruments, intangible assets followed by income or social impact. An investment project is an activity that involves the implementation of any action to achieve specific goals.

The paper [5] emphasizes that risk management requires a systematic assessment of the severity of risks affecting the project. The article notes the need to use different qualitative and quantitative methods of risk assessment of investment projects and their distinctive features, advantages, and disadvantages. The necessity of choosing the most expedient method of risk assessment for a specific project is determined.

The paper [6] assesses the risks to real estate with the construction of a fuzzy mathematical model. The authors emphasize the need to use several methods of quantitative risk assessment due to a certain subjectivity of the developed model.

The paper [7] considers the CAPM model for emerging capital markets and the DCF method, which allows assessing the attractiveness of both the business in general and the investment project of the enterprise in particular. The application of risk assessment methods to an investment project helps to assess its feasibility, the period when it will start to make a profit, and its level in the future.

In the paper [8] it is offered to use a method of expert estimations for estimation of risks of the investment project. This approach allows you to quantify the risks of the project, rank them and obtain a comprehensive indicator of risk assessment of the investment project.

The paper [9] proposes a methodology that modifies the capital pricing model (CAPM) using the discounted cash flow method. This approach allows you to assess the effectiveness of investment projects, risks, and management based on the information obtained.

The paper [10] analyzes the investment project for the construction of a greenhouse complex for growing vegetables. To achieve the planned key economic indicators of the project, it is necessary to reduce the negative impact of risk factors. Since the project did not provide for the analysis of project risks, namely there was no system of identified risks, qualitative and quantitative risk assessment, sensitivity analysis, break-even point, etc., the authors note the need for project risk management, namely mandatory funding conditions for project analysis risks.

The paper [11] proposes a mechanism for assessing and prioritizing risks. This will allow managers to make informed management decisions regarding risk prevention and speed up the recovery time from real risks.

In the paper [12] it is offered to consider risk in system stratification metamodeling system. The authors propose to increase the investment attractiveness, profitability, and competitiveness of the enterprise by reducing various types of costs by implementing a BPM-system based on the proposed stratification metamodeling system. A mandatory component of this system is a subsystem that takes into account the risk.

The paper [13] presents a model for assessing the risks of investment projects using Bayesian networks. The application of this approach is explained by the presence of different types of uncertainty and the need to formalize and process information taking into account uncertainty.

The paper [14] examines international risks and their impact on the implementation of the investment project. The authors compare the traditional NPV model and the NPV model taking into account the weight of entropy as a risk assessment of the investment project. The second model showed the best results and is offered as a basis for decision making.

The paper [15] uses a comprehensive assessment based on fuzzy logic to assess the security risk of an energy investment project. The model includes the definition of the factor characteristics of the object of evaluation, the establishment of a set of estimates, the establishment of a relationship matrix, the calculation of the weight of the index, fuzzy complex assessment. The practical implementation of the model demonstrated a risk value of 3.1154 (average risk).

In the paper [16], three models were developed to accurately predict the quality of project planning, based on both deterministic and fuzzy concepts, and the results show that the fuzzy model is more accurate and realistic than the deterministic one. Thus, the correct use of fuzzy theory will develop more accurate, realistic, and reliable models than deterministic ones.

Despite the significant achievements of scientists in the direction of risk assessment of investment projects of the enterprise, the further study requires a comprehensive assessment of investment risks using economic and mathematical modeling, namely fuzzy logic. After all, it is necessary to take into account both the probability of occurrence of each of the risks and their weights, the ability to take into account both qualitative and quantitative information in one system, comparing several alternative projects. This is necessary to manage the investment risks of the project, minimize unplanned costs and increase the level of competitiveness of the enterprise. In this regard, it is proposed to conduct a comprehensive risk assessment of the investment project using fuzzy set theory according to the methodology of determining a comprehensive assessment of the risk of bankruptcy of the enterprise A. Nedosekin [17], which is adapted to determine a comprehensive risk assessment of the investment project.

Fuzzy logic and fuzzy set theory have received a wide range of successful practical applications in various spheres of life. For example, in the paper [18] it is proposed to choose a solution in the presence of a large number of efficiency criteria based on fuzzy preference relations. This approach allows you to form a set of alternatives based on selected performance criteria, choose the best and make an effective management decision.

In the paper [19], economic and mathematical models for diagnosing the bankruptcy of the enterprise using the methods of fuzzy logic and developed a comprehensive analysis of the financial condition of the enterprise. 
Also, the application of fuzzy logic in the financial sector is presented in [20].

Special attention in today's conditions deserves research, which reflects the use of fuzzy logic to stabilize the epidemiological situation with COVID-19 [21].

\subsection{The aim and objectives of the research}

The study aims to develop an economic-mathematical model for determining a comprehensive risk assessment of an investment project based on fuzzy logic, taking into account the probability of each of the identified risks and the level of impact of each of them on the project.

To achieve this goal the following tasks were solved:

1) set the task and develop a descriptive model for determining a comprehensive risk assessment of the project;

2) to build a mathematical model of the problem of determining a comprehensive risk assessment of the project and to develop an algorithm for its solution;

3) generate input data using the opinions of experts;

4) build a hierarchical project risk tree;

5) determine the weights (Fishburn weights) of project risks;

6) select and describe membership functions and linguistic variables;

7) convert the initial data provided by experts from a score scale into linguistic terms;

8) to recognize qualitative input data on a linguistic scale;

9) determine a comprehensive risk indicator of the investment project;

10) to analyze the obtained complex indicator.

\section{Research methodology}

The proposed model can be implemented with the following input data:

- a set of expert assessments of the probability of project risks;

- hierarchy of existing project risks (a hierarchical tree of logical conclusion);

- system of relations of advantages of some risks over others (for one level of hierarchy).

The initial data of the model are:

- comprehensive quantitative risk assessment of the project;

- interpretation of the obtained complex project risk indicator.
The model involves the use of elements of fuzzy logic (logical inference tree, membership function, linguistic terms). Expert knowledge and the Fishburn method of scales were also used to determine the project risk weights.

Problem statement and development of a descriptive model for determining a comprehensive risk assessment of the project.

The task of determining a comprehensive risk assessment of the project within this study is implemented by a construction company, which assesses the risks of a new investment project for the construction of a residential complex. The experts identified the following types of risk, which are typical for the project of residential complex construction, and their components that affect the results of the project and selected for the formation of a comprehensive assessment $\left(R_{0}\right)$ :

1. Technical $R_{1}$ (risks of reassessment of project sustainability $R_{1.1}$; risks associated with the reassessment of additional opportunities for project development $R_{1.2}$ ).

2. External $R_{2}$ (risks of incorrect assessment of demand for the project $R_{2.1}$; risks associated with the nature of competition in the market $R_{2.2}$; risks associated with the solvency of the customer $R_{2.3}$; risks of the uncertainty of the external environment of the project $R_{2.4}$ ).

3. Organizational $R_{3}$ (risks for estimating the costs of project commercialization $R_{3.1}$; risks of potential losses from project implementation $R_{3.2}$; risks of underestimation of project development costs $R_{3.3}$; risks of the uncertainty of the internal project environment $R_{3.4}$ ).

Each of the risks has its probability of occurrence and level of impact on the successful implementation of the project.

It is necessary to determine a comprehensive indicator of the risk level of the project to make a management decision on the feasibility of this investment project and the necessary actions to increase the probability of successful project implementation, taking into account existing risks.

Mathematical model of the problem of determining a comprehensive risk assessment of the project and the algorithm for its solution.

In this situation, for a comprehensive assessment of project risks, it is advisable to consider the PRM model (Project Risk Model):

$$
P R M=<F, A, R>,
$$

where $F$ - the hierarchy of existing project risks (a hierarchical tree of logical conclusion);

$A$ - a set of qualitative assessments of each factor in the hierarchy (linguistic terms);

$R-$ a system of relations of advantages of some risks over others (for one level of hierarchy).

In this case:

$$
A=((L),(L M),(M),(H M),(H)),
$$


where $L$ - Low, $L M$ - LowMedium, $M$ - Medium, $H M$ HighMedium, $H$ - High.

$$
R=R i(r) R j \mid r \in(>, \approx),
$$

where $>-$ the ratio of preference;

where $\approx$ - equilibrium ratio.

The proposed model consists of the following stages:

Stage 1. Formation of initial data with the use of expert opinions.

Experts estimate the probability of risks using a scale from 0 to 100 points. For each indicator, points are added and the average is determined $C_{i}$ :

$$
C_{i}=\frac{\sum_{i=1}^{n} C_{i j}}{N},
$$

where $N$ - the number of interviewed experts;

$C_{i j}$ - the sum of points for each indicator.

Next, the concordance coefficient is determined by the formula:

$$
W=\frac{\sigma_{f}^{2}}{\sigma_{\max }^{2}}=\frac{\sum_{i=1}^{m}\left(a_{i}-\frac{1}{2} n \cdot(m+1)\right)^{2}}{\frac{1}{12} n^{2} \cdot m \cdot\left(m^{2}-1\right)},
$$

where $\sigma_{f}^{2}$ - the actual variance (SD) of the final (ordered, ranked) estimates provided by experts;

$\sigma_{\max }^{2}$ - dispersion of final (ordered) assessments, provided that the opinions of experts completely coincide;

$a_{i}$ - the total estimate obtained by the $i$-th object;

$m$ - the number of studied objects;

$n$ - the number of experts.

The materiality of the concordance coefficient is checked using $\chi^{2}$ with $(m-1)$ the number of degrees of freedom. Statistical characteristics are calculated by the formula:

$$
\chi^{2}=W \cdot n(m-1),
$$

Stage 2. Construction of a hierarchical risk tree of the project using the system of relations of advantages.

Stage 3. Determination of weights (Fishburne weights). For a system of declining benefits $N$ alternatives:

$$
p_{i}=\frac{2(N-i+1)}{(N+1) N}, \quad i=1 . . N .
$$

A system of equivalent $N$ alternatives - a set of identical weights:

$$
p_{i}=N^{-1}, \quad i=1 . . N .
$$

Stage 4. Selection and description of membership function and linguistic variables. Selected triangular membership function:

$$
\mu(x)=\left\{\begin{array}{ll}
0, & x \leq a \\
\frac{x-a}{b-a}, & a \leq x \leq b \\
c=x & b \leq x \leq c \\
c-b & c \leq x
\end{array},\right.
$$

where $\mu(x)$ - the membership function of linguistic terms ( 0 - does not belong, 1 - belongs to all 100\%); $a, b, c$ are some numerical parameters that take arbitrary actual values and are ordered by the relation $a \leq b \leq$ $c$. Parameters $a$ and $c$ characterize the base of the triangle, and parameter $b$ is its vertex.

Stage 5. Transformation of the initial data provided by experts on the probability of occurrence of each of the risks, from a score scale to linguistic terms. The obtained average scores of the probability of occurrence of each of the risks are translated into linguistic terms according to the selected membership function.

Stage 6. Recognition of qualitative input data on a linguistic scale:

$$
Z^{*}(a)=\left(\mu_{1}^{*}(a), \mu_{2}^{*}(a), \mu_{3}^{*}(a), \mu_{4}^{*}(a), \mu_{5}^{*}(a)\right),
$$

where $a$ - the value of the factor to be recognized;

$\mu_{i}^{*}(a)$ is membership function with linguistic terms $i$;

$\mu_{i}^{*}(a)$ is determined by the formula (9).

Stage 7. Determination of a complex indicator.

First, you need to convert all vectors $Z^{*}\left(x^{*}\right)$ in the hierarchy $F$ with weight $P$ according to the formula:

$$
\begin{array}{r}
\sum_{i=0}^{N} p_{i} \cdot\left(\mu_{i \cdot 1}, \mu_{i \cdot 2}, \mu_{i \cdot 3}, \mu_{i \cdot 4}, \mu_{i \cdot 5}\right)= \\
=\left(\sum_{i=1}^{N} p_{i} \cdot \mu_{i \cdot 1}, \sum_{i=1}^{N} p_{i} \cdot \mu_{i \cdot 2}, \sum_{i=1}^{N} p_{i} \cdot \mu_{i \cdot 3},\right. \\
\left.\sum_{i=1}^{N} p_{i} \cdot \mu_{i \cdot 4}, \sum_{i=1}^{N} p_{i} \cdot \mu_{i \cdot 5}\right)
\end{array}
$$

where $i$ - possible options for determining the membership function for each linguistic term.

Next, the vector can be determined, which will characterize the complex risk assessment of the project (taking into account the selected triangular membership function):

$$
A \_N=\sum_{i=1}^{5}(0.25 i-0.25) \cdot \mu_{0 i},
$$

where $(0.25 i-0,25)=(0 ; 0.25 ; 0.5 ; 0.75 ; 1)-$ nodal points of the triangular membership function, in which it is equal to 1 on a scale from 0 to 1 (nodal points at which the membership function refers to a certain linguistic term for 100 $\%)$ according to the formula $(14-18)$ and figure 2.

Stage 8. Interpretation of the obtained complex indicator.

\section{Results and discussion}

Consider the implementation of the model according to the problem.

Stage 1. Formation of initial data with the use of expert opinions.

Table 1 provides information provided by experts regarding the assessment of the probability of occurrence of each of the selected risks of the project on a scale from 0 to 100 points (ascending).

The concordance coefficient according to formula (5) is 0.7048 , which indicates that the opinions of experts are consistent. 
Checking the materiality of the concordance coefficient according to the formula (6) $\chi^{2}=63.44$.

The data in table $\left(\chi^{2}\right)$ for (10-1) degrees of freedom and confidence probability $(=0.95,=0.99,=0.999)$ show that the calculated value of the Pearson criterion $\chi^{2}$ is greater than the tabular (respectively 16.92; 21.67, and 27.88), which confirms the conclusion that experts agree.

Stage 2. Construction of a hierarchical tree of risks of the project using the system of relations of advantages.

The experts provided the following information on the risk-benefit ratios (figure 1).

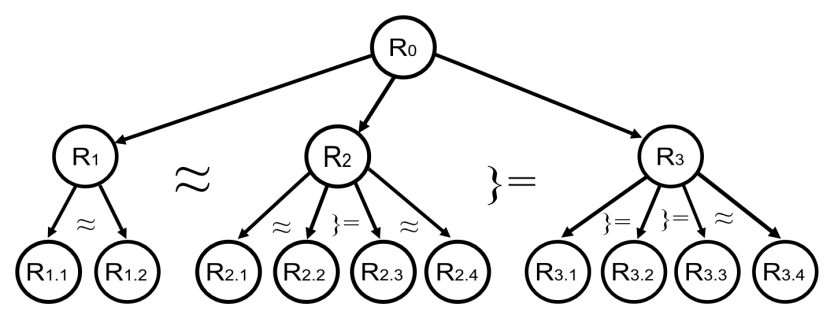

Figure 1. Hierarchical risk tree of the project with the indication of the system of relations of advantages

Figure 1 corresponds to the system of relations $R$ (formula 13).

$$
\begin{gathered}
R=\left(R_{1} \approx R_{2}>R_{3} ; R_{1.1} \approx R_{1.2} ; R_{2.1} \approx\right. \\
\approx R_{2.2}>R_{2.3} \approx R_{2.4} ; R_{3.1}>R_{3.2}>R_{3.3} \approx R_{3.4}
\end{gathered}
$$

The obtained system of preference ratios can be used to determine the risk weights of Fishburne weights.

Stage 3. Determination of weights (Fishburne weights)

According to formulas (7) and (8), as well as the system of preference relations (figure 1) formed a system of Fisher scales (table 2).

After convolving the weights of different levels of the hierarchy, the following generalized weights (level of influence) were obtained: $R_{1.1}=0.2000 ; R_{1.2}=0.2000$; $R_{2.1}=0.1333 ; R_{2.2}=0.1333 ; R_{2.3}=0.0667 ; R_{2.4}=$ $0.0667 ; R_{3.1}=0.0857 ; R_{3.2}=0.0571 ; R_{3.3}=0.0286$; $R_{3.4}=0.0286$.

The highest weights are in risks $R_{1.1}, R_{1.2}$, the lowest in $R_{3.3}, R_{3.4}$.

Stage 4. Selection and description of membership function and linguistic variables

The linguistic variable "Risk Level" was formed with a term set of values of A (formula 2). The triangular membership function (figure 2) with the following linguistic terms was chosen as membership functions: Low (L), Low Medium (LM), Medium (M), High Medium (HM), High $(\mathrm{H})$, distributed on a scale from 0 to 100 points.

The following system of equations corresponds to this membership function with linguistic terms:

$$
L: \mu_{1}(x)=\left\{\begin{array}{ll}
\frac{25-x}{25}, & 0 \leq x \leq 25 \\
0, & 25 \leq x
\end{array} .\right.
$$

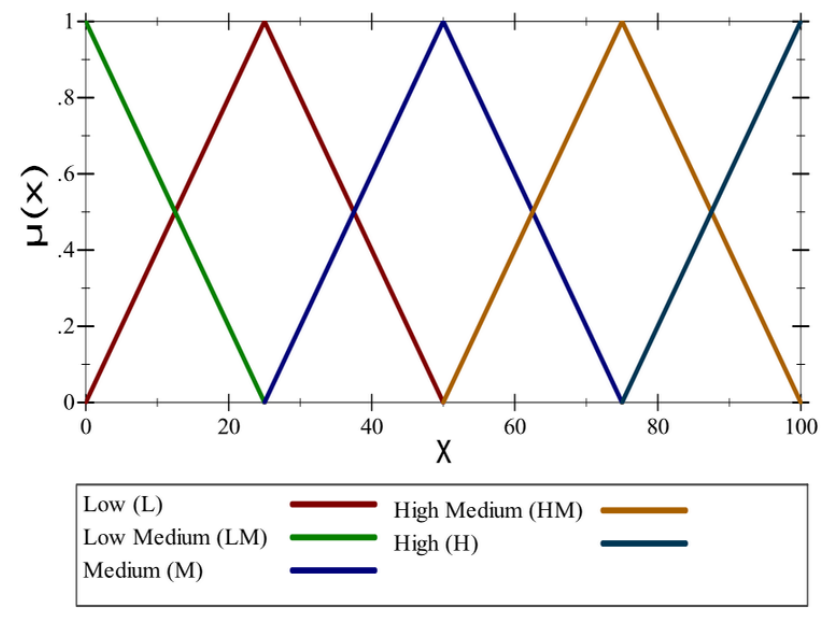

Figure 2. Triangular membership functions with linguistic terms Low (L), Low Medium (LM), Medium (M), High Medium (HM), High (H)

$$
\begin{gathered}
L M: \mu_{2}(x)= \begin{cases}\frac{x}{25}, & 0 \leq x \leq 25 \\
\frac{50-x}{25}, & 25 \leq x \leq 50 \\
0, & 50 \leq x\end{cases} \\
M: \mu_{3}(x)=\left\{\begin{array}{ll}
0, & x \leq 25 \\
\frac{x-25}{25}, & 25 \leq x \leq 50 \\
\frac{75-x}{25}, & 50 \leq x \leq 75 \\
0, & 75 \leq x
\end{array} .\right. \\
H M: \mu_{4}(x)=\left\{\begin{array}{ll}
0, & x \leq 50 \\
\frac{x-50}{25}, & 50 \leq x \leq 75 \\
\frac{100-x}{25}, & 75 \leq x \leq 100
\end{array} .\right. \\
H: \mu_{5}(x)=\left\{\begin{array}{ll}
0, & x \leq 75 \\
\frac{x-75}{25}, & 75 \leq x \leq 100
\end{array} .\right.
\end{gathered}
$$

Formulas (14-18) are based on formula 9 and figure 2.

Stage 5. Transformation of the initial data provided by experts on the probability of occurrence of each of the risks, from the score scale to the linguistic terms.

The scores of the probability of occurrence of each of the risks from table 1 are translated into linguistic terms (according to figure 2): Low (L), Low Medium (LM), Medium (M), High Medium (HM), High (H) (table 3).

According to the table, it can be seen that among the risks are risks, both with a low probability of occurrence and with a very high probability. The indication of two linguistic terms for risk indicates that the obtained average scores of experts are on the border of two terms.

Stage 6. Recognition of qualitative input data on a linguistic scale

According to formulas (14-18) the input data was recognized according to the linguistic scale (table 4). 
Table 1. Expert assessment of the probability of occurrence of each of the risks of the project in points

\begin{tabular}{ccccccccccccc}
\hline Risk & Ex1 & Ex2 & Ex3 & Ex4 & Ex5 & Ex6 & Ex7 & Ex8 & Ex9 & Ex10 & Values sum & Average value \\
\hline$R_{1.1}$ & 40 & 45 & 55 & 60 & 50 & 60 & 40 & 55 & 45 & 60 & 510 & 51.0 \\
$R_{1.2}$ & 60 & 65 & 75 & 70 & 80 & 70 & 75 & 65 & 55 & 60 & 675 & 67.5 \\
$R_{2.1}$ & 15 & 20 & 20 & 30 & 30 & 35 & 40 & 45 & 45 & 35 & 315 & 31.5 \\
$R_{2.2}$ & 60 & 80 & 75 & 65 & 85 & 100 & 85 & 90 & 95 & 100 & 835 & 83.5 \\
$R_{2.3}$ & 10 & 15 & 15 & 25 & 40 & 35 & 30 & 45 & 25 & 15 & 255 & 25.5 \\
$R_{2.4}$ & 60 & 45 & 55 & 50 & 60 & 40 & 40 & 55 & 60 & 70 & 535 & 53.5 \\
$R_{3.1}$ & 70 & 80 & 90 & 60 & 55 & 85 & 70 & 65 & 60 & 80 & 715 & 71.5 \\
$R_{3.2}$ & 55 & 60 & 60 & 45 & 80 & 65 & 45 & 75 & 80 & 85 & 650 & 65.0 \\
$R_{3.3}$ & 25 & 15 & 15 & 10 & 20 & 30 & 35 & 15 & 40 & 40 & 245 & 24.5 \\
$R_{3.4}$ & 95 & 90 & 100 & 70 & 80 & 65 & 55 & 85 & 90 & 100 & 830 & 83.0 \\
\hline
\end{tabular}

Table 2. Fishburne system of scales

\begin{tabular}{cccccc}
\hline $\mathrm{N}$ & $R$ & $p_{1}$ & $p_{2}$ & $p_{3}$ & $p_{4}$ \\
\hline 2 & $R_{1.1} \approx R_{1.2}$ & $1 / 2$ & $1 / 2$ & - & - \\
3 & $R_{1} \approx R_{2}>R_{3}$ & $2 / 5$ & $2 / 5$ & $1 / 5$ & - \\
4 & $R_{2.1} \approx R_{2.2}>R_{2.3} \approx R_{2.4}$ & $2 / 6$ & $2 / 6$ & $1 / 6$ & $1 / 6$ \\
4 & $R_{3.1}>R_{3.2}>R_{3.3} \approx R_{3.4}$ & $3 / 7$ & $2 / 7$ & $1 / 7$ & $1 / 7$ \\
\hline
\end{tabular}

In the table, the cells corresponding to the values of linguistic variables obtained using risk analysis models are given the recognized value according to formulas (14-18). In other cells " 0 " is put.

Thus, the probability of risk R1.1 in accordance with expert opinions and linguistic terms refers to the level of Medium (96\%), High Medium (4\%); $R_{1.2}-$ Medium (30\%), High Medium (70\%); $R_{2.1}$ - Low Medium (74\%), Medium (26\%); $R_{2.2}$ - High Medium (66\%), High (34\%); $R_{2.3}$ - Low Medium (98\%), Medium (2\%); $R_{2.4}-$ Medium (86\%), High Medium (14\%); $R_{3.1}-$ Medium (14\%), High Medium (86\%); $R_{3.2}$ - Medium (40\%), High Medium $(60 \%) ; R_{3.3}-$ Low (2\%), Low Medium (98\%); $R_{3.4}-$ High Medium (68\%), High (32\%).

Stage 7. Determination of a complex indicator

At the next stage, a comprehensive risk indicator of the investment project is determined, based on fuzzy sets. According to formula (11) found the vector:

$$
\begin{array}{r}
\sum_{i=0}^{N} p_{i} \cdot\left(\mu_{i \cdot 1}, \mu_{i \cdot 2}, \mu_{i \cdot 3}, \mu_{i \cdot 4}, \mu_{i \cdot 5}\right)= \\
=(0.0006 ; 0.1920 ; 0.3802 ; 0.3727 ; 0.0545) .
\end{array}
$$

But according to the selected membership function, the nodal points in which the membership function is 1 are equal to $(0 ; 25 ; 50 ; 75 ; 100)$. To find the integral exponent, use formula (12) and multiply the corresponding exponents of both vectors and find their sum.

$$
A \_N=51.8194=R_{0} \text {. }
$$

Thus, the complex risk indicator of the investment project is 51.8194 points.

Stage 8. Interpretation of a complex indicator.

According to formulas (14) - (18) and figure 2, the value of the complex risk indicator is average $(93 \%)$ on the border of above average ( $7 \%$ ). $R_{1.1}$ and $R_{1.2}$ risk have the

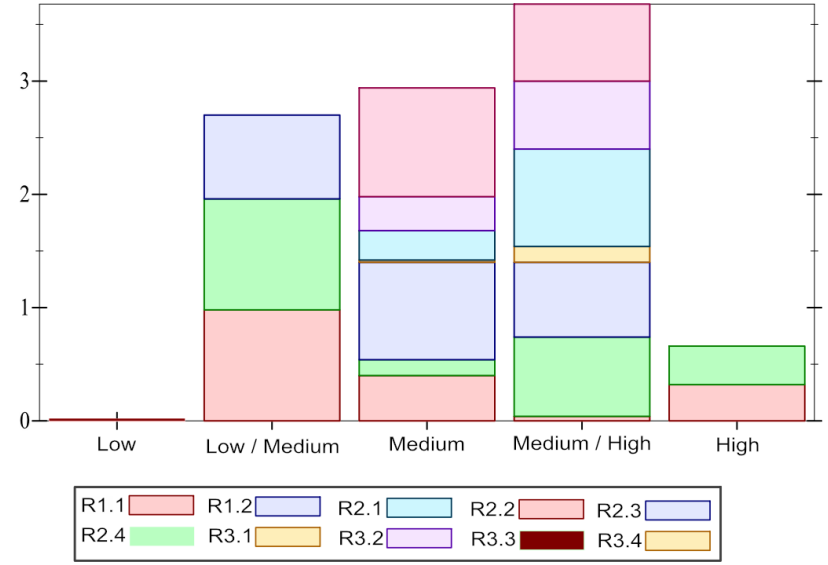

Figure 3. Components of a complex indicator of investment project risks and their compliance with linguistic terms

greatest impact (according to weighting factors) (figure 3).

According to figure 3, the highest risks belong to the level of High Medium, in second place the level of Medium, and in third place - Low Medium.

Figure 4 shows a risk map of the project (according to table 4). The $y$-axis reflects the probability of risk (in ascending order), and the $x$-axis shows the risk weight (in ascending order). The bold line shows the critical limit of the level of risk. Those risks that are above this line are critical for the project and require a priority management decision to transfer them from the critical (red-purple) zone to the green zone.

Therefore, the most critical for the project are risks $R_{1.2}$ (risks associated with the reassessment of additional opportunities for project development (errors in the assessment of alternative technologies and choice of technology and equipment for the project, failure to develop project capacity), risk $R_{1.1}$ project sustainability: risk of confidence that the new project is guaranteed success due to its unique qualities, even when imitating it, risk of confidence in the company's potential for exclusive cooperation), $R_{2.2}$ (risks associated with the nature of competition in the market, namely risks strong competitive influence in the target markets of the enterprise), $R_{2.1}$ (risks of incorrect estimation of demand for the project), $R_{3.1}$ (risks for estimation 
Table 3. Risks and their levels in linguistic terms

\begin{tabular}{|c|c|c|c|}
\hline $\begin{array}{l}\text { Risk } \\
\text { number }\end{array}$ & $\begin{array}{l}\text { Risk des- } \\
\text { ignation }\end{array}$ & Name of risk & $\begin{array}{l}\text { Risk level (probability of } \\
\text { occurrence) }\end{array}$ \\
\hline 1 & $R_{1.1}$ & Risks of reassessment of project sustainability & Medium, High Medium \\
\hline 2 & $R_{1.2}$ & $\begin{array}{l}\text { Risks associated with the reassessment of additional project devel- } \\
\text { opment opportunities }\end{array}$ & Medium, High Medium \\
\hline 3 & $R_{2.1}$ & Risks of incorrect assessment of demand for the project & Low Medium, Medium \\
\hline 4 & $R_{2.2}$ & Risks associated with the nature of competition in the market & High Medium, High \\
\hline 5 & $R_{2.3}$ & Risks associated with the solvency of the customer & Low Medium, Medium \\
\hline 6 & $R_{2.4}$ & Risks of the uncertainty of the external environment of the project & Medium, High Medium \\
\hline 7 & $R_{3.1}$ & Risks for estimating the costs of project commercialization & Medium, High Medium \\
\hline 8 & $R_{3.2}$ & Risks of potential losses from project implementation & Medium, High Medium \\
\hline 9 & $R_{3.3}$ & derestimation of project devel & Low, Low Medium \\
\hline 10 & $R_{3.4}$ & Risks of the uncertainty of the internal environment of the project & High Medium, High \\
\hline
\end{tabular}

Table 4. Matrix of the actual distribution of values by fuzzy sets

\begin{tabular}{lcclllll}
\hline \multirow{2}{*}{ Risk } & Weights (level of influence) & $x$ & & \multicolumn{5}{c}{ Membership functions $\mu$} \\
& & & $\begin{array}{l}\text { Low } \\
\left(\mu_{1}(x)\right)\end{array}$ & $\begin{array}{l}\text { Low Medium } \\
\left(\mu_{2}(x)\right)\end{array}$ & $\begin{array}{l}\text { Medium } \\
\left(\mu_{3}(x)\right)\end{array}$ & $\begin{array}{l}\text { High Medium } \\
\left(\mu_{4}(x)\right)\end{array}$ & $\begin{array}{l}\text { High } \\
\left(\mu_{5}(x)\right)\end{array}$ \\
\hline$R_{1.1}$ & 0.2000 & 5.01 & 0 & 0 & 0.96 & 0.04 & 0 \\
$R_{1.2}$ & 0.2000 & 67.5 & 0 & 0 & 0.30 & 0.70 & 0 \\
$R_{2.1}$ & 0.1333 & 31.5 & 0 & 0.74 & 0.36 & 0 & 0 \\
$R_{2.2}$ & 0.1333 & 83.5 & 0 & 0 & 0 & 0.66 & 0.34 \\
$R_{2.3}$ & 0.0667 & 25.5 & 0 & 0.98 & 0.02 & 0 & 0 \\
$R_{2.4}$ & 0.0667 & 53.5 & 0 & 0 & 0.86 & 0.14 & 0 \\
$R_{3.1}$ & 0.0857 & 71.5 & 0 & 0 & 0.14 & 0.86 & 0 \\
$R_{3.2}$ & 0.0571 & 65.0 & 0 & 0 & 0.40 & 0.60 & 0 \\
$R_{3.3}$ & 0.0286 & 24.5 & 0.02 & 0.98 & 0 & 0 & 0 \\
$R_{3.4}$ & 0.0286 & 83.0 & 0 & 0 & 0 & 0.68 & 0.32 \\
\hline
\end{tabular}

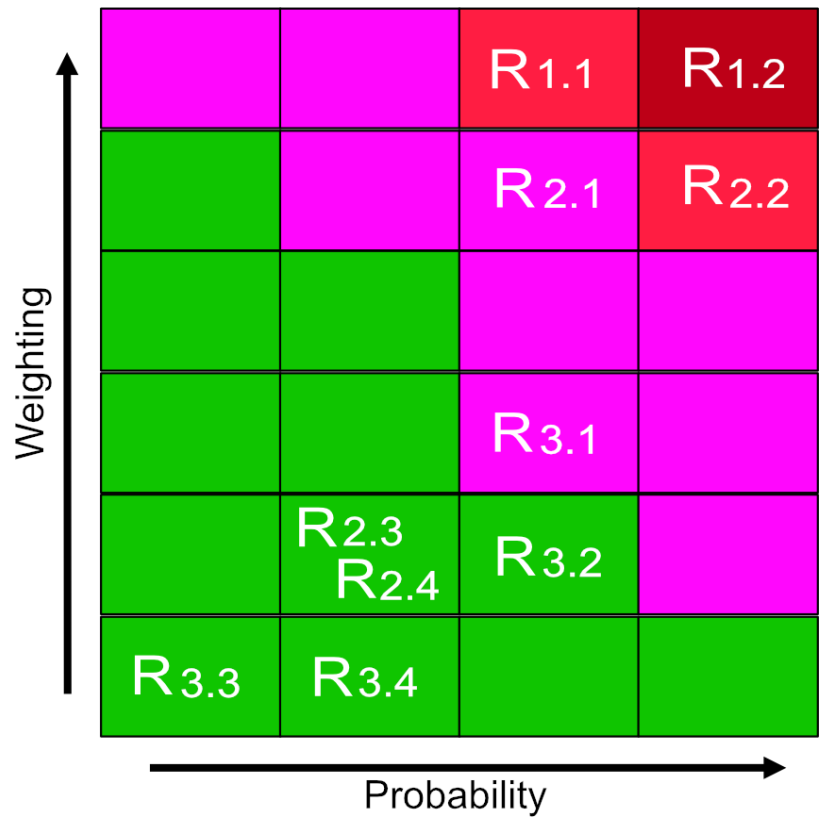

Figure 4. Risk map of the investment project

of expenses of commercialization of the project). To translate them into an acceptable green zone requires in-depth comprehensive marketing research, development, and implementation of additional measures to ensure the qual- ity of raw materials; application of sanctions to suppliers, up to replacement of equipment; staff training during construction; search and implementation of reserves to reduce production costs; transition to alternative sources; reduction of the share of imported materials and spare parts due to the maximum use of domestic, primarily local, etc.

This approach to obtaining a comprehensive assessment should also be used to select one of several alternative projects because the best will be the one where the overall risk assessment of the project is less.

If we compare the obtained complex indicator with the complex indicator obtained by ordinary convolution (the sum of weights per indicator level), ie the average scores from table 1 and the corresponding weights, the complex indicator will be 57.2123. Thus, it is possible to notice the difference in obtaining a complex indicator by different methods, but the application of fuzzy logic allows to work with both quantitative and qualitative input indicators and to use easy-to-understand linguistic terms.

\section{Conclusions}

1. The task of determining a comprehensive risk assessment of the project within this study is implemented by a construction company, which assesses the risks of a new investment project for the construction of a residential complex. The experts identified the types of risk and their components that af- 
fect the results of the project and selected for the formation of a comprehensive assessment. These include technical (risks of reassessment of project sustainability; risks associated with the reassessment of additional opportunities for project development), external (risks of incorrect assessment of project demand; risks associated with the nature of competition in the market; risks associated with the solvency of the customer; risks of the uncertainty of the external environment of the project), organizational (risks of estimating the costs of project commercialization; risks of potential losses from project implementation; risks of underestimation of project development costs; risks of the uncertainty of the internal environment of the project).

2. The mathematical model of the problem of determining a comprehensive assessment of project risks consists of the following components: hierarchy of existing project risks (a hierarchical tree of logical conclusion); a set of qualitative assessments of each factor in the hierarchy (linguistic terms); system of relations of advantages of some risks over others (for one level of hierarchy). The proposed Project Risk Model consists of the following stages: formation of initial data using expert opinions; construction of a hierarchical project risk tree; determination of weighting factors (Fishburne weights) of project risks; selection and description of membership function and linguistic variables; conversion of input data provided by experts from a score scale into linguistic terms; recognition of qualitative input data on a linguistic scale; determination of a complex indicator of investment project risks; interpretation of a complex indicator.

3. Initial data were formed using the opinions of experts: the experts provided an estimate of the probability of occurrence of each of the selected risks of the project on a scale from 0 to 100 points (ascending). The risks related to the nature of competition in the market and the risks of uncertainty in the internal environment of the project are most likely.

4. A hierarchical tree of risks of the project is constructed with the indication of the system of relations of advantages that gives the chance to form weighting factors using Fishburne weights.

5. According to the system of relations of preferences, Fisher's system of weights is formed. The highest weights are the risks associated with the revaluation of additional project development opportunities and the risks of revaluation of project sustainability.

6. The linguistic variable "Level of risk" with the term set of values A was formed. The triangular membership function with the following linguistic terms was chosen as membership functions: Low (L), Low Medium (LM), Medium (M), High Medium (HM), $\operatorname{High}(\mathrm{H})$, distributed on a scale from 0 to 100 points.
7. The initial data provided by experts on the probability of occurrence of each of the risks were converted from a score scale to the linguistic terms Low (L), Low Medium (LM), Medium (M), High Medium (HM), High (H).

8. Recognition of qualitative input data on a linguistic scale is carried out. The highest total value according to the triangular membership function in the linguistic term High Medium.

9. Determination of a complex indicator of the level of project risks. Its value is $\mathbf{5 1 . 8 1 9 4}$ points.

10. The analysis of the obtained complex indicator shows that the total level of risk of the investment project is average (93\%) on the verge of above average $(7 \%)$. The constructed risk map shows that the most critical for the project implementation are the risks associated with the reassessment of additional opportunities for project development; risks of reassessment of project sustainability; risks associated with the nature of competition in the market; risks for estimating the costs of project commercialization. To reduce them requires in-depth comprehensive marketing research, development, and implementation of additional measures to ensure the quality of raw materials; application of sanctions to suppliers, up to replacement of equipment; staff training during construction; search and implementation of reserves to reduce production costs; transition to alternative sources; reduction of the share of imported materials and spare parts due to the maximum use of domestic, primarily local, etc.

The presented approach allows determining a comprehensive assessment of the risks of the investment project of the enterprise, which indicates its universality and creates conditions for its acceptability for different enterprises.

\section{References}

[1] I. Chaikovska, M. Chaikovskyi, Eastern-European journal of enterprise technologies 3, 34 (2020)

[2] D. Peskova, J. Khodkovskaya, V. Charikov, Risk assessment of investment projects in the digital economy, in European Proceedings of Social and Behavioural Sciences EpSBS, edited by S.I. Ashmarina, V.V. Mantulenko (European Publisher, London, United Kingdom, 2019), Vol. 79 of GCPMED 2019, pp. 1170-1176

[3] M. Waszkiewicz, T. Grzeszczyk, Entrepreneurship and Sustainability Issues 7, 2363 (2020)

[4] R. Shchur, S. Kropelnytska, I. Fufalko, Logos pp. 16-18 (2020)

[5] E. Bogomolova, MATEC Web of Conferences 239, 08021 (2018)

[6] M. Zhang, W. Yang, Physics Procedia 24, 1815 (2012) 
[7] A. Voronov, M. Karmanov, I. Kiseleva, V. Kuznetsov, L. Leontieva, International Journal of Engineering And Technology 7, 336 (2018)

[8] G.Z. Nizamova, M.M. Gayfullina, D.R. Musina, A.Y. Tumanova, A.A. Battalova, IOP Conference Series: Materials Science and Engineering 880, 012111 (2020)

[9] S.G. Galevskiy, IOP Conference Series: Materials Science and Engineering 866, 012040 (2020)

[10] L.Z. Bayguzina, G.A. Galimova, A.A. Sukiasyan, Tools for Estimating the Risk Effect on the Investment Project Efficiency, in Proceedings of the International Scientific Conference "Far East Con" (ISCFEC 2020) (Atlantis Press, 2020), pp. 529-536, ISBN 978-94-6252-929-8, ISSN 2352-5428, https://doi.org/10.2991/aebmr. k. 200312.075

[11] S.E. Griffis, J.M. Whipple, Transportation Journal 51, 428 (2012)
[12] V. Vitlinskyi, V. Glushchevsky, SHS Web Conf. 65, 08002 (2019)

[13] O. Efimova, D. Koroleva, Humanitarian Balkan Research 4, 57 (2019)

[14] C. Chong, Eurasia. Journal of Mathematics, Science \& Technology Education 12, 2451 (2016)

[15] Yang, Taihua, Li, Zhixiang, Qin, Jing, E3S Web Conf. 118, 01039 (2019)

[16] H.H.E. Mousalami, MOJ Civil Engineering 5, 5 (2019)

[17] A. Nedosekin, Ph.D. thesis, St. Petersburg University, St. Petersburg, Russia (2003)

[18] P.M. Hryhoruk, N.A. Khrushch, S.S. Grygoruk, Scientific Bulletin of Polissia 4, 92 (2017)

[19] A. Matviychuk, Fuzzy Economic Review XV, 21 (2010)

[20] J. Diaz, E. Coba, P. Lopez, Contaduría y Administración 62, 1687- (2017)

[21] Y. Fu, K. Liang, Computer Methods and Programs in Biomedicine 197 (2020) 